\title{
IMPACT OF TWO DIFFERENT DESIGNS AND MATERIALS ON FRACTURE RESISTANCE OF OCCLUSAL VENEERS (IN VITRO STUDY)
}

Yasmin Elgendy ${ }^{*}$, Manal Mohamed Abo Madina** and Nesma Elgohary ${ }^{* * *}$

\begin{abstract}
Statement of the problem: Occlusal veneer restorations represent a minimal invasive alternative to traditional crowns in treatment of severely worn dentition. However, the data regarding the mechanical performance of occlusal veneers designs and materials are still controversial.

Aim of study: Evaluation of the effect of using two different designs and materials on fracture resistance of occlusal veneer restorations.

Materials and Methods: Thirty-two freshly extracted premolars were randomly divided into two main groups $(n=16)$ according to preparation design: Group B: butt joint preparation design and Group M: Modified occlusal veneer design. Each main group was further subdivided into two subgroups $(n=8)$ according to type of restorative material used for occlusal veneer fabrication: Lithium disilicate and polymer-infiltrated ceramic network. Occlusal veneer restorations were fabricated by $\mathrm{CAD} / \mathrm{CAM}$ technology and then cemented to their corresponding teeth using dual cured adhesive resin cement. Fracture resistance test was done using universal testing machine. The load needed for fracture of each specimen was registered automatically in Newtons $(\mathrm{N})$ by a special software. Data were collected, tabulated and statistically analyzed.
\end{abstract}

Results: Student's $t$-test results revealed that there was no statistically significant difference regarding the two variables (preparation design and material type). Also, Two-way ANOVA test results showed that there was no statistically significant difference regarding the interaction between the two variables in this study $(\mathrm{P}=0.309)$.

Conclusion: There was no effect of preparation designs and material types on fracture resistance of occlusal veneers. The fracture resistance for all study groups exceeded the reported range of human masticatory forces.

KEY WORDS: Occlusal veneer, preparation designs, fracture resistance, Lithium disilicate, Polymer-infiltrated ceramic network.

* Fixed Prosthodontics Dept., Faculty of Dentistry, Mansoura University, Mansoura, Egypt

** Professor, Fixed Prosthodontics Dept., Faculty of Dentistry, Mansoura University, Mansoura, Egypt

*** Instructor, Fixed Prosthodontics Dept., Faculty of Dentistry, Mansoura University, Mansoura, Egypt 


\section{INTRODUCTION}

Loss of tooth substance could be attributed to several causes such as: dental caries, erosion, abrasion and attrition. Clinically, tooth wear could have drawbacks such as loss of vertical dimensions, pulpal complications, esthetic and functional impairments. ${ }^{(1)}$

Preservation of tooth structure was the main aim of restorative dentistry, so great attention had been paid to conservative and esthetic restorations such as indirect partial coverage restorations (inlays, onlays, overlays or partial crowns).(2)

Occlusal veneers were suggested as an alternative to more invasive treatment modalities for occlusal surface reconstructions to restore the musculoskeletal harmony, occlusal stability and to achieve patient satisfaction. ${ }^{(3,4)}$

Various designs for occlusal veneers were introduced such as: straight-beveled finish line design, butt joint preparation design, modified occlusal veneer preparation design with circumferential finish line, with two proximal slots or with intracoronal cavity, $90^{\circ}$-rounded shoulder design, minimal invasive chamfer preparation design, buccal occlusal veneer preparation design, occlusal and lingual coverage design, occlusal, lingual and mesial coverage design, occlusal, lingual, mesial and distal coverage design, occlusal reduction with central groove design and occlusal reduction with round shoulder and central groove design, but data regarding the effect of the preparation design of occlusal veneers on their fracture resistance were controversial. ${ }^{(5)}$

Moreover, occlusal veneers were fabricated from plenty of restorative materials such as: (Feldspathic ceramics, Leucite-reinforced ceramic, Zirconia-reinforced lithium silicate, Zirconia, Resin Nano Ceramic, Zirconia-silica ceramic in a resininterpenetrating matrix, Lithium disilicate and Polymer-infiltrated ceramic network) using computer-aided design/ computer-aided manufacturing
(CAD/CAM) technology that became popular during the last decade for restorations fabrication, but data regarding the proper occlusal veneers restorative material were controversial. ${ }^{(6,7)}$

Lithium disilicate was a synthetic glass-ceramic that had been considered the strongest glass-ceramic due to the high number of microstructural, interlocking, needle-like lithium disilicate crystals embedded in the glassy matrix. ${ }^{(8)}$ It was widely used in dentistry because of its excellent biocompatibility, the continuous development of its mechanical properties through using better microstructures and new processing techniques, its adhesive characteristics that allowed preservation of sound tooth structure and its good esthetic quality. ${ }^{(9-12)}$

Polymer-infiltrated ceramic network (Vita Enamic) was a hybrid ceramic CAD/CAM material comprised of $86 \%$ pre-sintered porous feldspathic ceramic network (silicon dioxide, aluminum oxide, sodium oxide, potassium oxide, zirconia, calcium oxide) infiltrated with $14 \%$ polymers such as: urethane methacrylate (UDMA) and triethylene glycol dimethacrylate (TEGDMA). ${ }^{(13)}$ It had low elastic modulus close to dentin that enabled it to dissipate stresses evenly during mastication resulting in high damage tolerance. Also, It could be repaired easily by composite resins and could be milled easily. ${ }^{(14,15)}$

CAD/CAM technology allowed overcoming most of the difficulty and technical complexity of fabricating these veneers and enabled professionals to make restorations easily and quickly in a single session. ${ }^{(5)}$

Due to the controversy among researches regarding occlusal veneers preparation designs and materials and their effect on fracture resistance, which was an essential factor that predicted the restorations success and survivability, this study was performed to provide more data about their effect on fracture resistance especially with premolars as there were few data regarding premolars restored 
by occlusal veneer restorations. The hypothesis of this study was that both the preparation designs and the materials would have a significant effect on the fracture resistance of occlusal veneer restorations.

\section{MATERIALS AND METHODS}

Thirty-two extracted premolars were collected from Maxillofacial and Oral Surgery department clinic, faculty of dentistry, Mansoura University. Teeth were cleaned from calculus and soft tissue remnants by ultrasonic scaler and then examined carefully under 3.5x magnification using (Galilean dental loupes, Gain Express, China) to make sure that they were free from caries and cracks. Digital caliper was used to make sure that all selected teeth had comparable dimensions. The selected teeth were immersed in 5\% sodium hypochlorite for 15 minutes and stored in saline till used. ${ }^{(16)}$

Each tooth was embedded in epoxy resin 2 $\mathrm{mm}$ below cemento-enamel junction to facilitate handling, using a teflon ring with the dimensions ( $2.5 \mathrm{~cm}$ in diameter and $2 \mathrm{~cm}$ in hight) and a custommade paralleling device to ensure its centralization.

Specimens were randomly divided into two main groups according to preparation design: Group B: Butt joint design, Group M: Modified occlusal veneer design.
Each main group was further subdivided into two subgroups according to type of restorative material used for occlusal veneer fabrication: Subgroup BL: Butt joint design and lithium disilicate, Subgroup BH: Butt joint design and hybrid ceramic, Subgroup ML: Modified occlusal veneer design and lithium disilicate, Subgroup MH: Modified occlusal veneer design and hybrid ceramic.

\section{Teeth Preparation:}

Dental surveyor (Marathon 103, Korea) with low speed handpiece, depth grooves and indices were used to standardize teeth preparation. Teeth were prepared into two designs: Butt joint design which included only occlusal reduction $1.5 \mathrm{~mm}$ at cusp tips and $1 \mathrm{~mm}$ at central grooves and Modified occlusal veneer design which included occlusal reduction $1.5 \mathrm{~mm}$ at cusp tips and $1 \mathrm{~mm}$ at central groove along with $1 \mathrm{~mm}$ circumferential deep chamfer finish line. (Figure 1)

\section{Fabrication of the occlusal veneers}

An optical impression was performed by scanning of the prepared teeth by an optical scanner (Identica Hybrid series GmbH, Germany).

Exocad chairside CAD software, version 2.2 Valetta, exocad $\mathrm{GmbH}$ was used for designing occlusal veneer restorations. The thickness of occlusal veneers were adjusted to be $1 \mathrm{~mm}$ at cenral grooves and $1.5 \mathrm{~mm}$ at cusp tips. ${ }^{(17)}$

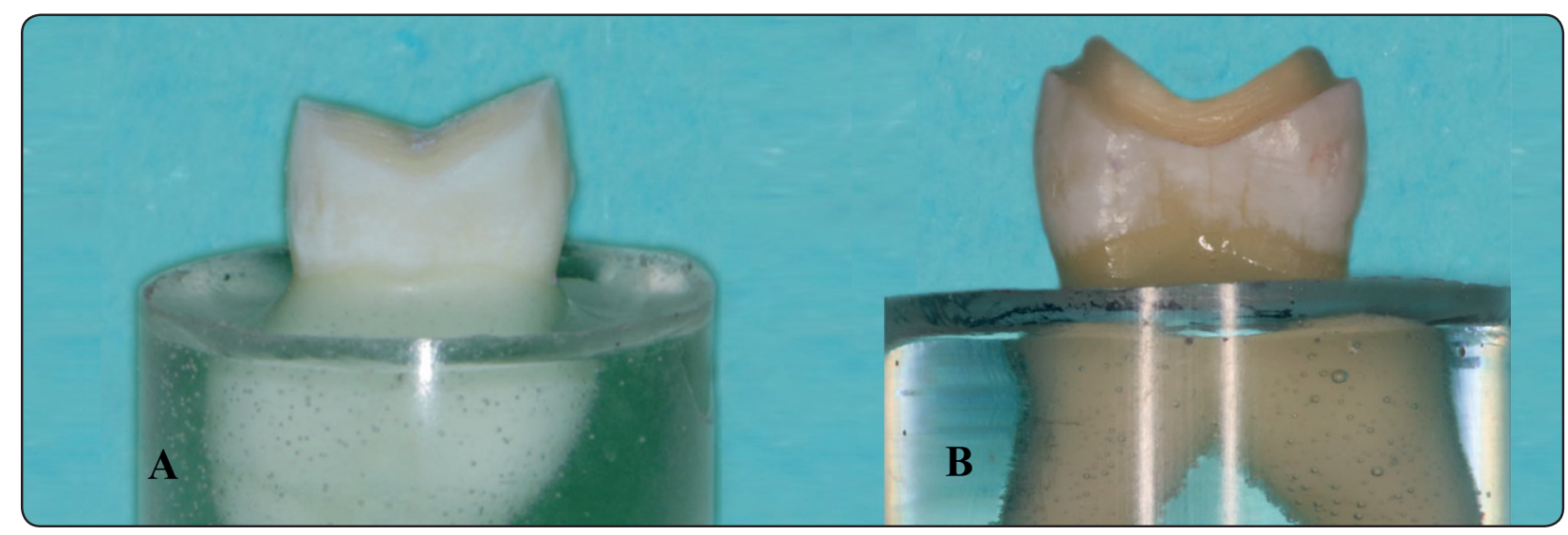

Fig. (1): A) Butt joint design preparation.

B) Modified occlusal veneer design preparation. 
All lithium disilicate and polymer-infiltrated ceramic network occlusal veneer restorations were milled out of IPS e.max CAD blocks and Vita Enamic blocks respectively using a wet 5-axis milling machine (Imes-Icore GmbH,Germany, CORTEC 250 i ).

After finishing and polishing, all occlusal veneers were checked for adaptation and thickness.

All IPS e.max CAD occlusal veneer restorations were crystallized at $840{ }^{\circ} \mathrm{C}$ for $20 \mathrm{~min}$ to reach their maximum strength and esthetics using Programat P500 Ivoclar Vivadent furnace.

\section{Cementation}

The fitting surfaces of Lithium disilicate (IPS e.max CAD) restorations were conditioned with 9\% hydrofluoric acid (Ultradent, USA) for $20 \mathrm{sec}$, while the fitting surfaces of polymer-infiltrated ceramic network (Vita Enamic) restorations were conditioned for $60 \mathrm{sec}^{(3)}$ The conditioned surfaces were rinsed with water spray properly and air-dried gently. Then, silane coupling agent (Ultradent,USA) was applied with a microbrush on the fitting surfaces for $60 \mathrm{sec}$ and then air dried for $5 \mathrm{sec}^{(3)}$

Prepared teeth were conditioned with 37\% phosphoric acid (Travlin etching gel, Technodent) for $30 \mathrm{sec}$. Then, the etched surfaces were rinsed carefully with water spray for $10 \mathrm{sec}$ and air-dried gently to avoid dessication. ${ }^{(18)}$ The bonding agent (Prime \& bond, Dentsply) was applied with a microbrush and agitated for $20 \mathrm{sec}$, dried gently for $5 \mathrm{sec}$ and light cured for $10 \mathrm{sec}$.

Dual cured adhesive resin cement (Calibra Ceram, Dentsply, USA) was applied to the fitting surfaces of the restorations using syringe tip.

Each occlusal veneer restoration was seated on its corresponding tooth with finger pressure and excess cement was removed by an explorer after light curing by (Foshan J, China) light cure apparatus for $5 \mathrm{sec}$ (tack curing).

Each specimen was inserted into specially designed cementation device to guarantee obtaining a uniform cement layer thickness for all specimens by subjecting all specimens to the same seating load $1 \mathrm{Kg}$ during cementation procedures. ${ }^{(18)}$ All surfaces were light cured for $20 \mathrm{sec}$ per side by wave length $420-480 \mathrm{~nm}$ and light intensity $850-1200 \mathrm{w} / \mathrm{cm}^{2}$. ${ }^{(17)}$

\section{Fracture resistance test}

All specimens were loaded vertically till fracture in a universal testing machine (Model 3345, Instron, USA). An indenter with $6 \mathrm{~mm}$ diameter was used to apply compressive load perpendicular to specimens along their long axis with a crosshead speed of $1 \mathrm{~mm} /$ min till fracture. ${ }^{(5)}$ To distribute loads evenly, a 0.5 $\mathrm{mm}$ tin foil was positioned between the indenter and the specimen. The load needed for fracture of each specimen was recorded automatically in Newtons (N) using a special software. ${ }^{(18)}$

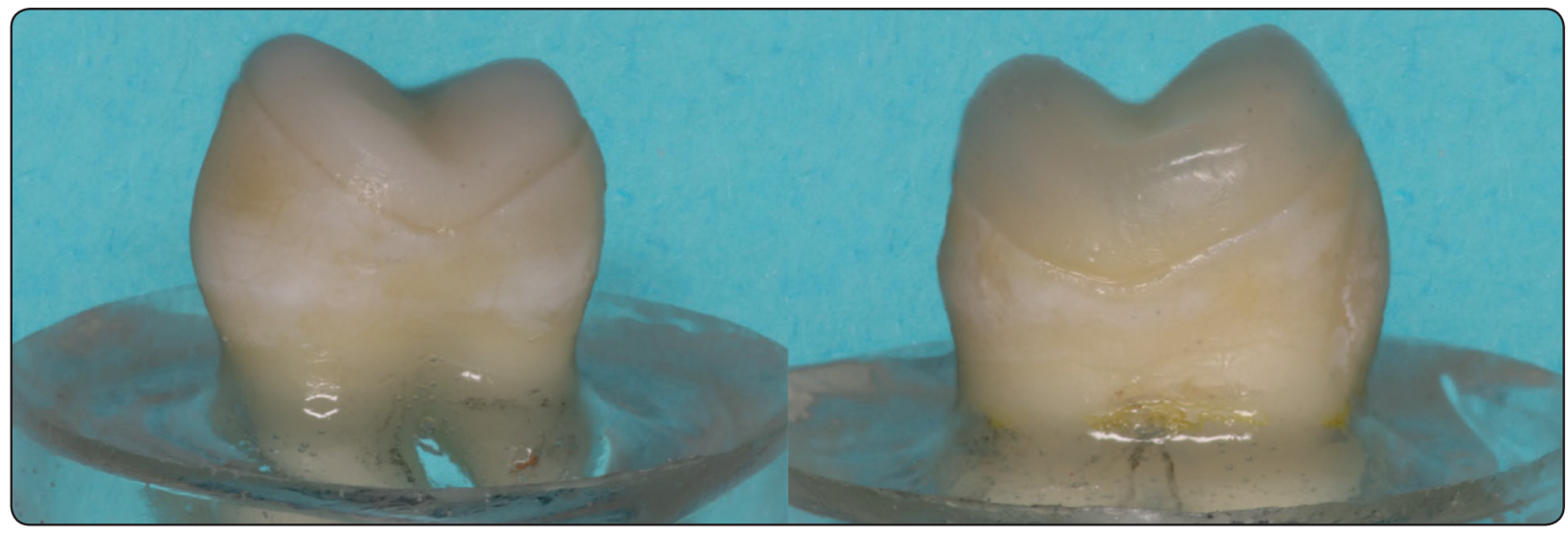

Fig. (2): Specimens after cementation. 


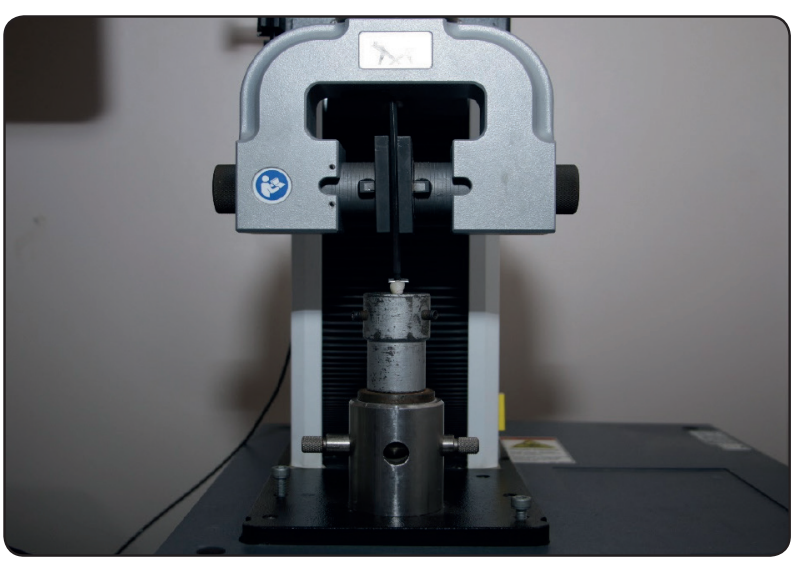

Fig. (3): Specimen within the universal testing machine.

\section{RESULTS}

Data were collected, tabulated then analyzed using the computer program SPSS (Statistical package for social science) version 26.0.

\section{Effect of the preparation design on the fracture resistance of occlusal veneers:}

Student's test (Unpaired) was used for comparing between fracture resistance of occlusal veneers preparation designs within each ceramic material and it was found that regardless of the ceramic material, modified occlusal veneer preparation design showed non-significant difference compared to butt joint preparation design. ( Table 1)

TABLE (1): Student's test (Unpaired) used for comparing between fracture resistance of occlusal veneers preparation designs within each ceramic material

\begin{tabular}{|c|c|c|c|c|}
\hline & Group B & Group M & $\mathrm{t}$ & $\mathrm{P}$ \\
\hline Material L & $819.65 \pm 233.95$ & $803.43 \pm 246.06$ & 0.135 & 0.89 \\
\hline Material H & $773.42 \pm 152.02$ & $949.68 \pm 370.72$ & -1.244 & 0.23 \\
\hline
\end{tabular}

Data expressed as mean $\pm S D$

SD: standard deviation

P: Probability *: significance $p<0.05$

Test used: Student's t-test (Unpaired)
Effect of ceramic material on the fracture resistance of occlusal veneers

Student t-test (Unpaired) was used for comparing between fracture resistance of occlusal veneer ceramic materials within each preparation design and it was found that regardless of the preparation design, hybrid ceramic occlusal veneers showed nonsignificant difference from lithium disilicate occlusal veneers. (Table 2)

TABLE (2): Student t-test (Unpaired) used for comparing between fracture resistance of occlusal veneer ceramic materials within each preparation design

\begin{tabular}{|c|c|c|c|c|}
\hline & Material L & Material H & $\mathrm{t}$ & $\mathrm{P}$ \\
\hline Group B & $819.65 \pm 233.95$ & $773.42 \pm 152.02$ & 0.45 & 0.65 \\
\hline Group M & $803.43 \pm 246.06$ & $949.68 \pm 370.72$ & 0.40 & 0.37 \\
\hline
\end{tabular}

P: Probability *: Significance $<0.05$

According to Two-way ANOVA test that was used for detecting the effect of each variable and the interaction between them, it was found that the preparation design, the ceramic material and the interaction between both of them had a statistically non-significant difference on fracture resistance of occlusal veneers. (Table 3 )

TABLE (3): Two-way ANOVA results that represent the effect of different variables on fracture resistance of occlusal veneers

\begin{tabular}{|c|c|c|c|c|c|}
\hline $\begin{array}{c}\text { Source of } \\
\text { variations }\end{array}$ & $\begin{array}{c}\text { Type III } \\
\text { Sum of } \\
\text { Squares }\end{array}$ & df & $\begin{array}{c}\text { Mean } \\
\text { Square }\end{array}$ & F & P \\
\hline Designs & 51223.203 & 1 & 51223.203 & 0.743 & 0.396 \\
\hline Materials & 20005.500 & 1 & 20005.500 & 0.290 & 0.594 \\
\hline $\begin{array}{l}\text { Designs * } \\
\text { Materials }\end{array}$ & 74092.289 & 1 & 74092.289 & 1.075 & 0.309 \\
\hline
\end{tabular}

$$
\text { P: Probability *: significance } p<0.05
$$




\section{Fracture mode}

The fractured specimens showed fracture mode within Mode I, II and V, but the majority of fractured specimens were within mode I and II. Most of Lithium disilicate occlusal veneer fractured specimens were within mode (I) whereas most of polymer-infiltrated ceramic network fractured specimens were within mode (II).

The mode of fracture was categorized according to Burke's classification into the following ${ }^{(2)}$ :

Mode I: Crack or fracture in the restoration only.

Mode II: Fracture in the restoration involving a small part of tooth structure.

Mode V: Catastrophic fracture of the tooth and the restoration.

\section{DISCUSSION}

The purpose of this in vitro study was to investigate the effect of using two different preparation designs and materials on fracture resistance of occlusal veneer restorations.

It was hypothesized that both the preparation design and the type of material would affect occlusal veneers fracture resistance.

According to the results of our study: preparation design and type of material had non-significant effect on fracture resistance of occlusal veneers, so the hypothesis was rejected.

In our study, natural teeth were chosen over epoxy resin dies because of their strength and bonding ability that represented better clinical situation. ${ }^{(19)}$ Digital caliper was used to make sure that all selected teeth had comparable dimensions to eliminate potential differences. ${ }^{(20)}$ Then all teeth were stored in saline to preserve them till use as saline protected them from drying out and becoming brittle. ${ }^{(16)}$

Lithium disilicate (IPS e.max CAD) was chosen in our study because of its superior mechanical properties, good bonding characteristics, long-term clinical acceptability and favorable esthetics. ${ }^{(20)}$

Polymer-infiltrated ceramic network (Vita Enamic) was chosen in our study as it was a material that combined the advantages of ceramics and resins, so it was an easily milled and repaired material with high damage tolerance. ${ }^{(14)}$

The decision of using the two preparation designs (butt joint and modified occlusal veneer design) was to investigate the effect of increasing the surface area of adhesion and marginal preparation on the fracture resistance of occlusal veneers.

For standardization of teeth preparation, heavy body index and depth grooves were used as a guide during occlusal reduction and a dental surveyor was used to standardize the circumferential finish line preparation. ${ }^{(17)}$

For standardization of occlusal veneer restorations, CAD/CAM technology was used to standardize the thickness and the anatomy of the restorations and to avoid laboratory errors. ${ }^{(21)}$

Adhesive resin cement was chosen in our study as it was found that all ceramic restorations cemented using adhesive resin cements had greater fracture resistance than those cemented using traditional cements. ${ }^{(22)}$

Moreover, in our study we used total etch technique because it was reported that the use of total-etch technique enhanced the bond strength up to $28 \mathrm{MPa}$ within enamel and $13-20 \mathrm{MPa}$ within dentin that lead to improving the fracture resistance. $(23,24)$

Fracture resistance test was chosen in our study as it played a crucial role in determining the longevity of the restorations. ${ }^{(21)}$

Regarding the effect of the preparation design on fracture resistance of occlusal veneers in our study, the type of the preparation design had non-significant effect and that might be because the point of 
loading during fracture resistance test was centralized on specimens away from the finish line. ${ }^{(25)}$

Our results agreed with Abdelhameed et al. $(2018)^{(5)}$ and Emam Z and Aleem N. (2020) ${ }^{(7)}$ who found that there was no effect of the preparation design on occlusal veneers fracture resistance .

Regarding the effect of the materials on fracture resistance of occlusal veneers in our study, it was non-significant. This could be attributed to that polymer-infiltrated ceramic network had higher bond strength to resin-based adhesive materials than lithium disilicate, so its bond strength increased its resistance to fracture and compensated for its lower flexural strength. ${ }^{(26,27)}$

These results agreed with Al-Akhali et al. (2018) ${ }^{(28)}$, Ioannidis et al. (2019) $)^{(3)}$ Gurpinar et al. (2020)(29) and Zamzam et al. (2021) ${ }^{(30)}$ who found that lithium disilicate occlusal veneers had non-significantly different fracture resistance from polymer-infiltrated ceramic network occlusal veneers.

On contrast, our results disagreed with AlAkhali et al. (2017) ${ }^{(18)}$,Andrade et al. (2018) ${ }^{(31)}$, Rabeae et al. (2020) ${ }^{(32)}$ and Albelasy et al. (2021) $)^{(33)}$ who found that lithium disilicate occlusal veneers showed significantly higher fracture resistance than those made of polymer-infiltrated ceramic network and this could be attributed to that lithium disilicate had higher mechanical properties than polymerinfiltrated ceramic network. ${ }^{(27)}$

Also, the results of our study disagreed with Maeder et al. (2019) ${ }^{(34)}$ and Emam Z and Aleem N. $(2020)^{(7)}$ who found that polymer-infiltrated ceramic network occlusal veneers had significantly higher fracture resistance than lithium disilicate occlusal veneers and this could be attributed to that they subjected the specimens to cyclic fatigue loading as polymer-infiltrated ceramic network demonstrated more favourable resistance to fatigue due to the presence of polymers in its microstructure that enhanced its resistance to crack propagation. ${ }^{(35)}$
The limitation of this study was that it was a laboratory study which lacked simulating the oral environmental conditions through thermocycling and cyclic loading.

\section{CONCLUSIONS}

1- Lithium disilicate and polymer-infiltrated ceramic network occlusal veneers had comparable fracture resistance that exceeded the reported range of human masticatory forces, so they can be used as a conservative alternative to full coverage crowns for treatment of severely worn dentition.

2- There were no effect of the preparation designs and the material types on fracture resistance of occlusal veneers.

3- Fracture mode of the specimens proved that polymer-infiltrated ceramic network had greater bond strength to resin-based adhesive materials than lithium disilicate.

\section{Recommendations}

1- Further investigations should be conducted including different ceramic materials and new preparation designs.

2- The use of artificial chewing simulator to simulate clinical condition effects on fracture resistance of occlusal veneers.

3- In vivo studies should be done to evaluate occlusal veneers as the assessment of their clinical performance would be the best judgment for their success and longevity.

\section{REFERENCES}

1. Smith B and Knight J. A comparison of patterns of tooth wear with aetiological factors. Br Dent J1984;157:16-19.

2. Falahchai M, Babaee Hemmati Y, Neshandar Asli H and Rezaei E. Effect of tooth preparation design on fracture resistance of zirconia-reinforced lithium silicate overlays. J Prosthodont 2020;29:617-622. 
3. Ioannidis A et al. Ultra-thin occlusal veneers bonded to enamel and made of ceramic or hybrid materials exhibit load-bearing capacities not different from conventional restorations. J Mech Behav Biomed Mater 2019;90:433440 .

4. Magne P, Schlichting LH, Maia HP and Baratieri LN. In vitro fatigue resistance of $\mathrm{CAD} / \mathrm{CAM}$ composite resin and ceramic posterior occlusal veneers. J Prosthet Dent 2010;104:149-157.

5. M Abdelhameed A, H Abd-El Aziz M and A Hamza T. In vitro study to evaluate the effect of different material types and preparation designs on the fracture resistance of occlusal veneers. Al-Azhar J Dent Sci 2018;21:65-71.

6. Mohamed KA, El Mahallawi OSED, Zaki AAEL. In-vitro Fatigue Resistance of Bonded Posterior Occlusal Veneers: A Systematic Review. Indian J Sci Technol 2016;9:1-8.

7. Emam ZN and Aleem NA. Influence of Different Materials and Preparation Designs on Marginal Adaptation and Fracture Resistance of CAD/CAM Fabricated Occlusal Veneers. E.D.J 2020;66:439-452.

8. Oh S-C, Dong J-K, Lüthy H and Schärer P. Strength and microstructure of IPS Empress 2 glass-ceramic after different treatments. Int J Prosthodont 2000;13:468-472.

9. SILVA LHd et al. Dental ceramics: a review of new materials and processing methods. Braz Oral Res 2017;31:134-146.

10. Tete $\mathrm{S}$ et al. Proliferation and adhesion capability of human gingival fibroblasts onto zirconia, lithium disilicate and feldspathic veneering ceramic in vitro. Dent Mater 2014;33:7-15.

11. Valenti M and Valenti A. Retrospective survival analysis of 261 lithium disilicate crowns in a private general practice. Quintessence Int 2009;40:573-579.

12. Solá-Ruiz MF et al. Survival rates of a lithium disilicatebased core ceramic for three-unit esthetic fixed partial dentures: a 10-year prospective study. Int J Prosthodont 2013;26:175-180.

13. Duarte S, Sartori N and Phark J-H. Ceramic-reinforced polymers: CAD/CAM hybrid restorative materials. Curr Oral Health Rep 2016;3:198-202.

14. Chirumamilla G, Goldstein CE and Lawson NC. A 2-year retrospective clinical study of enamic crowns performed in a private practice setting. J Esthet Restor Dent 2016; 28:231-237.
15. Coldea A, Swain MV and Thiel N. In-vitro strength degradation of dental ceramics and novel PICN material by sharp indentation. $\mathrm{J}$ Mech Behav Biomed Mater 2013;26:34-42.

16. Angerame D, De Biasi M, Agostinetto M, Franzò A and Marchesi G. Influence of preparation designs on marginal adaptation and failure load of full-coverage occlusal veneers after thermomechanical aging simulation. J Esthet Restor Dent 2019;31:280-289.

17. Kotb S, Shaker A, Halim C. Fatigue resistance and 3D finite element analysis of machine-milled ceramic occlusal veneers with new preparation designs versus conventional design: an in vitro study. F1000Research 2019;8:10381054 .

18. Al-Akhali M, Chaar MS, Elsayed A, Samran A, Kern M. Fracture resistance of ceramic and polymer-based occlusal veneer restorations. J Mech Behav Biomed Mater. 2017;74:245-250.

19. Chitmongkolsuk S, Heydecke G, Stappert C and Strub JR. Fracture strength of all-ceramic lithium disilicate and porcelain-fused-to-metal bridges for molar replacement after dynamic loading. Eur J Prosthodont Restor Dent 2002;10:15-22.

20. Hussein M and Mohsen C. Bond strength and microleakage of different designs of occlusal veneers. NeuroQuantology 2021;19:62-66.

21. Hassan SM and El Mekkawi W. Influence of different preparation designs on fracture resistance of fullcoverage occlusal veneers after thermo-mechanical aging simulation. Al-Azhar Assiut Dent J 2020;3:145-154.

22. Piwowarczyk A, Bender R, Ottl P and Lauer H-C. Longterm bond between dual-polymerizing cementing agents and human hard dental tissue. Dent Mater 2007;23:211217.

23. Fortin D, Swift Jr EJ, Denehy GE and Reinhardt JW. Bond strength and microleakage of current dentin adhesives. Dent Mater 1994;10:253-538.

24. Al-Wahadni AM, Hussey DL, Grey $\mathrm{N}$ and Hatamleh MM. Fracture resistance of aluminium oxide and lithium disilicate-based crowns using different luting cements: an in vitro study. J Contemp Dent Pract. 2009;10:51-58.

25. Clausen J-O, Tara MA and Kern M. Dynamic fatigue and fracture resistance of non-retentive all-ceramic fullcoverage molar restorations. Influence of ceramic material 
and preparation design. Dent Mater 2010;26:533-538.

26. Duan Y and Griggs JA. Effect of elasticity on stress distribution in CAD/CAM dental crowns: glass ceramic vs. polymer-matrix composite. J Dent 2015;43:742-749.

27. Bindl A, Lüthy H and Mörmann WH. Strength and fracture pattern of monolithic CAD/CAM-generated posterior crowns. Dent Mater 2006;22:29-36.

28. Al-Akhali M, Kern M, Elsayed A, Samran A and Chaar MS. Influence of thermomechanical fatigue on the fracture strength of CAD-CAM-fabricated occlusal veneers. J Prosthet Dent 2019;121:644-650.

29. GÜRPINAR B, ÇELAKIL T, BACA E and EVLİOĞLU G. Fracture resistance of occlusal veneer and overlay $\mathrm{CAD} / \mathrm{CAM}$ restorations made of polymer-infiltrated ceramic and lithium disilicate ceramic blocks. J Ege Univ Sch Dent 2020;41:131-142.

30. Zamzam H, Olivares A and Fok A. Load capacity of occlusal veneers of different restorative CAD/CAM materials under lateral static loading. J Mech Behav Biomed Mater 2021;115:104290-104302.
31. Andrade J et al. Effect of different computer-aided design/ computer-aided manufacturing (CAD/CAM) materials and thicknesses on the fracture resistance of occlusal veneers. Oper Dent 2018;43:539-548.

32. Rabeae HS, Mohsen CA and Amgad SW. Assessment of Fracture Force of CAD-CAM-fabricated Occlusal Veneer Restorations with Different Thicknesses. Indian J Public Health Res Dev 2020;11:1131-1136.

33. Albelasy E, Hamama HH, Tsoi JK and Mahmoud SH. Influence of material type, thickness and storage on fracture resistance of CAD/CAM occlusal veneers. J Mech Behav Biomed Mater 2021;119:104485-104494.

34. Maeder $M$ et al. Load-bearing capacities of ultra-thin occlusal veneers bonded to dentin. J Mech Behav Biomed Mater 2019;95:165-171.

35. Leung BT, Tsoi JK, Matinlinna JP and Pow EH. Comparison of mechanical properties of three machinable ceramics with an experimental fluorophlogopite glass ceramic. J Prosthet Dent 2015;114:440-446. 